\title{
From Innovation to Scale: Policy Engagement for Enhanced Community-based Depression Care in Vietnam
}

\author{
Jill Murphy, Vu Cong Nguyen, Leena Chau, John O'Neil, Nguyen Van Hoi, Harry Minas
}

\section{Introduction}

Like many low and middle-income countries, Vietnam is facing a substantial, and possibly growing, burden of mental illness. While prevalence data are limited, a 2000 epidemiological survey by the National Psychiatric Hospital indicated the ten most common mental disorders affected approximately $15 \%$ of the population (National Psychiatric Hospital No 1. 2002). Prevalence data for depression in Vietnam are limited, but studies suggest that the prevalence in the general population is on par with global rates (Minas, Edington et al. 2017), with prevalence rates of up to $20 \%$ among post-partum women (Fisher, Mello et al. 2012, Fisher, Tran et al. 2013). It is estimated that depression in Vietnam makes up 2.88 percent of disability adjusted life years (DALYs) and $6.83 \%$ of years lived with disability (YLDs) (Minas, Edington et al. 2017). Depression has a considerable negative impact on functional ability, socioeconomic status and wellbeing for persons affected and their families (Kohn, Saxena et al. 2004).

While the government of Vietnam has taken steps to improve the delivery of mental health services including for depression in the community through the Community Mental Health Program (CMHP), in reality only $2 \%$ of those enrolled in the program are treated for depression ( $\mathrm{Ng}$, Than et al. 2011). The CMHP covers less than $70 \%$ of communes in the country $(\mathrm{Ng}$, Than et al. 2011, Minas, Edington et al. 2017) and predominantly consists of the distribution of medications for people living with psychosis and epilepsy (Izutsu, Tsutsumi et al. , Murphy, Corbett et al. 2018). While the CMHP has led to improved in-service training about mental health for primary care providers involved with CMHP program management, knowledge and training about depression remain very limited (Murphy, Corbett et al. 2018).

While numerous challenges exist to the improvement of depression service availability and access in Vietnam, a number of initiatives are contributing to the advancement of communitybased depression care. Both the Ministry of Health $(\mathrm{MoH})$ and the Ministry of Labour, Invalids and Social Affairs (MOLISA) have policy mandates to improve community-based depression care. In collaboration with MOLISA, the Mental Health in Adults and Children-Frugal Innovations (MAC-FI) project team, based at Simon Fraser University in Canada, has been working to adapt, test and scale-up a depression intervention that is delivered by the primary health care and social services sectors. Building on a foundation of mental health policy development by $\mathrm{MoH}$ and MOLISA, and of support for mental health policy and systems strengthening spearheaded by the University of Melbourne (UoM), the MAC-FI project has involved a fruitful and novel partnership between researchers from Vietnam, Canada, Australia, and policy makers in Vietnam. Successful policy engagement is essential to the scale-up of mental health 
interventions beyond the research phase, promoting their sustainability and integration into health systems (Eaton, McCay et al. 2011).

In this chapter, we describe the process of policy engagement through the phases of the MACFI project in the context of mental health policy in Vietnam, identifying challenges and facilitators to policy engagement. We also identify and discuss lessons learned and their implications for the broader field of global mental health research and policy engagement for the scale-up for community-based mental health care.

\section{Background}

\section{Vietnam MH policy and service delivery context}

The contemporary Vietnamese mental health system (Luong, La et al. 2016, Minas, Edington et al. 2017) has its origins in the French colonial period $(1858$ - 1954) when the first mental asylum was established in Bien Hoa, near Saigon, in 1919, and in the 1930s when French law regulating asylum care was applied in Indochina. The second asylum, near Hanoi, was opened in 1934. It was not until 1954 that a Vietnamese psychiatrist (trained in France) was appointed as director of the Psychiatric Hospital of South Vietnam. These developments occurred in the context of the First Indochina War that ended with the defeat of the French and the partition of Vietnam into North and South in 1954. Vietnam was not re-united until the end of the Second Indochina War in 1975. During this second period there was considerable progress in mental health care in both northern and southern regions. The Department of Neurology and Psychiatry of Hanoi Medical University was established in 1957, the Association for Neurology, Psychiatry, and Neurosurgery was established in 1962, and the National Psychiatric Hospital was established near Hanoi in 1963. In the north the government began building provincial psychiatric hospitals and a Department of Psychiatry established in 1969 at Bach Mai Hospital, at around the same period as the de-institutionalisation movement was gathering pace and general hospital departments of psychiatry were being established in Western countries (Luong, La et al. 2016, Minas, Edington et al. 2017).

The period since re-unification in 1975 may be seen as the modern era for Vietnam's mental health system development. Today, across Vietnam's 63 provinces and municipalities, there are 36 psychiatric hospitals, 24 departments of mental health in provincial social protection centres (run by Ministry of Labor, Invalids and Social Affairs - MOLISA) and 25 psychiatry departments in provincial general hospitals. (Luong, La et al. 2016) District hospitals in the 644 districts play little or no role in diagnosis, treatment and care for persons with mental disorders, other than provision of limited outpatient services by some district hospitals. While the development of the primary health care system has been a high priority for the Ministry of Health, primary health centres (commune health stations, of which there are 11,000 across the country) play a limited role in mental health. Commune health stations are responsible for detecting new cases, carrying out initial assessment, and referring when appropriate to provincial psychiatric hospitals. Psychiatric diagnosis, psychotropic drug prescribing, and inpatient mental health care may only be done at provincial and central psychiatric hospitals. Patients who have been 
discharged from provincial psychiatric hospitals, may be followed up and drugs, which have been prescribed by hospital staff, may be distributed to patients in the community. The primary health care network currently does not have the capacity to provide essential mental health services. (Luong, La et al. 2016) (Vuong, Ginneken et al. 2011)

Mental health services are extremely limited in Vietnam. There is an insufficient number of mental health specialists to meet the needs of citizens- with 1.70 psychiatrists and 11.52 psychosocial care providers per 100,000 population (Kakuma, Minas et al. 2011) resulting in the majority of the population lacking access to care. This is comparable to many low and middleincome countries, where between $76 \%$ and $85 \%$ of people with severe mental illness lack access to care (World Health Organization 2013). Services are often concentrated in inaccessible and overstrained tertiary-care facilities, stemming from a history of French colonization and its institutional approaches to treatment (Minas, Edington et al. 2017). Treatment often focuses solely on pharmacological approaches, with counseling and psychosocial interventions being even more limited (Vuong, Ginneken et al. 2011).

Vietnam's mental health system is comprised of four levels (Luong, La et al. 2016): 1) central; 2) provincial; 3) district; and 4) commune (community), each of which is responsible for different aspects of funding and service delivery (Luong, La et al. 2016). The Ministry of Health (MoH) and the Ministry of Labor, Invalids and Social Affairs (MOLISA) are responsible for different but overlapping components of the mental health system. $\mathrm{MoH}$ is responsible for managing the network of national and provincial psychiatric hospitals and services in primary care clinics, and managing a National Institute of Mental Health. MOLISA is responsible for overseeing the social protection system that provides income support to poor families, including those with a mentally ill family member, and rehabilitation and social support services to persons with mental illness. MOLISA also runs a network of social protection centres that provide residential care for persons with persistent and severe mental disorders.(Minas, Edington et al. 2017).

MoH included mental health as a National Health Target Program in 1998, an initiative comprised of education about mental health and mental illness and training of commune health station staff (doctors and nurses). This initiative was an expression of the commitment to shift from a sole reliance on psychiatric hospitals to an approach that includes mental health service provision in the community, through commune health stations (Minas, Edington et al. 2017). The National Target Program did not specifically include any attention to rehabilitation and social care. While $\mathrm{MoH}$ and MOLISA have historically worked in parallel to provide care to individuals with mental illness, there is now a concerted and sustained effort from both to focus on enhancing community-based mental health care, including for depression (Minas, Edington et al. 2017). However, there is inadequate capacity to comprehensively respond to depression in the community arising from a shortage of skilled healthcare workers, fragmented and constrained funding, and gaps in policy implementation due in part to a lack of an overarching and effective mental health law (Minas, Edington et al. 2017), and no broadly agreed model of primary mental health care for depression. 
In 2014, the Government of Vietnam prioritized strengthening community-based mental health services in their National Mental Health Strategy for 2015-2020 (Minas, Edington et al. 2017) along with integrating mental health care into primary health care services (Luong, La et al. 2016). This Strategy aligns with the WHO Mental Health Action Plan 2013-2020 (World Health Organization 2013) and with other associated health initiatives. The Strategy provides opportunities for the implementation of innovative approaches to deliver mental health services, including for depression. Unfortunately, the draft National Mental Health Strategy, developed by a process broad consultation across all regions and sectors in Vietnam, has not yet been approved and implemented by government. Another landmark development occurred in 2011, when the Government of Vietnam introduced a national reform priority to develop communitybased social support and rehabilitation services for people with mental illness (Minas, Edington et al. 2017). Although MOLISA and MoH's mandates are different, there is increasing recognition and advocacy for a community-based mental health system led collaboratively by the two ministries working closely together. This is reflected in their joint action for developing an integrated community-based mental health care system, including the development of the National Mental Health Strategy 2016-2025 (Minas, Edington et al. 2017) which also included contributions from other sectors.

The government is committed to improving community-based mental health care and is keen to apply evidence-based research to guide policy change. As a reflection of this, they have committed to: "1) developing infrastructure and equipment; 2) developing human resources; 3) developing and implementing integrated and sustainable community-based service delivery models for promotion, prevention, early detection, treatment and recovery; 4) raising community awareness and participation; and 5) increasing accountability of government at all levels" (Minas, Edington et al. 2017). While social workers have historically been absent from the mental health system, due to changing policy recognizing the key role they can play in delivering mental health services - particularly for assisting with integration back into the community after discharge from hospital - there is now a cadre of recently trained social workers with mental health training to help provide comprehensive services at the community level.

\section{Mental health policy engagement in Vietnam}

The development of mental health services and strengthening of mental health research in Vietnam has benefited from an extensive network of collaborations between Vietnam and other countries, including partnerships with universities, such as the Karolinska Institute in Sweden, Vanderbilt University in the USA, the Universities of Melbourne and Queensland in Australia, and with mental health institutions in France, the USA and other countries. Though the government of Vietnam's work to strengthen the mental health system and shift towards community-based care began only two decades ago, a great deal of progress has been made.

The University of Melbourne has worked with colleagues in Vietnam on mental health system development since 1994 (Minas 1994, Minas 1997). An early focus on equity-oriented strategies for health (Hung, Minas et al. 2000) proved to be very influential, with the Vietnamese language 
publication (Hung, Minas et al. 2001) being widely used as a policy and planning resource within the Ministry of Health. Activities supported by UoM have been part of a coherent approach to mental health system development (Minas 2012) and have included: conferences and workshops; leadership training for senior policy makers and practitioners in Melbourne and in Vietnam, visits to Melbourne by policy-makers and senior departmental officers from $\mathrm{MoH}$, MOLISA, Ministry of Education and Training, Ministry of Planning and investment, and Ministry of Finance; WHO consultancies on various aspects of mental health system development; research projects and mental health system development projects. An evaluation of the system of social protection centres commissioned by WHO (Minas 2009) played a significant role in the development of the national 1215 Program on Community Based Social Support and Rehabilitation for People with Mental Disorders.

Two examples of mental health system development projects have been the National Taskforce for Mental Health System Development in Vietnam Project (2010-2014) and the Vietnam Mental Health Consortium Project (2013-2915), both of which were financially supported by Atlantic Philanthropies, with additional support from AusAID (Minas, Edington et al. 2017). These projects have relied on collaboration with United Nations agencies (WHO and UNICEF), and international and local non-governmental organizations (Vietnam Veterans of America Foundation, Basic Needs, and Research and Training Centre for Community Development), as well as extensive collaboration with $\mathrm{MoH}$ and MOLISA. These two projects, and other collaborative work done over many years, have contributed to building political commitment for mental health (Caldas de Almeida JM, Minas et al. 2014), strengthening human resources (Kakuma, Minas et al. 2014), focusing on mental health research priorities for Vietnam and building networks for this purpose (Collins, Tomlinson et al. 2014), and moving towards integration of health and social care in the community and strengthening human rights and sustainability (Minas 2014).

The outcomes of these two overlapping projects have included the development of a draft National Mental Health Strategy (2016-2025); a national survey of mental health system resources; participation by 75 senior Fellows from Vietnam in the intensive 4-week Melbournebased International Mental Health Leadership Program from 2010-2013 (Beinecke, Minas et al. 2010) and, in collaboration with the National Institute of Mental Health, development and delivery of a one-week Leadership for Mental Health System Development Program in each of the six regions of Vietnam, in which more than 200 senior officers from $\mathrm{MoH}$ and MOLISA agencies from across all 63 provinces have participated. The Mental Health Consortium Project has specifically focused on enabling closer policy collaboration between MOLISA and MoH, resulting in the issuing of joint circulars and other forms of practical high level collaboration.

The current context of policy engagement through the MAC-FI project has built on this longstanding collaboration between study investigators and partners in Vietnam.

The Institute of Population, Health and Development has a long history of engagement with policy makers across many sectors in Vietnam. PHAD is one of the leading public health research institutes in Vietnam and since 2009 has supported different ministries, including $\mathrm{MoH}$, 
MOLISA and the Ministry of Science and Technology, to use research findings to develop policies. In 2013, PHAD began working in the area of community-based mental health, engaging with MOLISA and $\mathrm{MOH}$ to support policy development and to provide technical assistance to the government of Vietnam's National Mental Health Program.

Simon Fraser University (SFU) has also been involved in policy engagement for mental health systems strengthening in Vietnam. In 2014, on the recommendation of the Vietnam Mental Health Consortium Project management group, researchers from the Centre for Applied Research in Mental Health and Addiction (CARMHA) at SFU and at the University of Hue were engaged by MOLISA and UNICEF Vietnam to conduct an assessment of the mental health service system in Vietnam, with an emphasis on the social welfare and labour sector (Goldner, Murphy et al. 2015). The purpose of this assessment was to inform the reform of the mental health services system in Vietnam to better address the needs of people with mental disorders. This included revisiting the role of Social Protection Centres and Social Work Centres, which are residential facilities offering varying levels of treatment and rehabilitation for people with severe mental illness. This work involved a review of policy and planning documents, published and unpublished research studies, and grey literature. It also included meetings and interviews with a range of stakeholders in four provinces across Vietnam, including: government leaders from several ministries and departments at national, district and municipal levels, health service providers, patients and their families, representatives of NGO's, staff and managers of social protection and social work centres, representatives from Commune People's Committees, and academics. The findings of the assessment led to recommendations that included investment in increased human resources for mental health service delivery, enhanced community-based care and improved quality of institutional treatment, improved collaboration across ministries and departments, and development of legislation to protect people living with mental illness and their families (Goldner, Murphy et al. 2015) .

In 2015, representatives from CARMHA/SFU, the Institute of Population, Health and Development (PHAD) and the University of Melbourne were invited to attend and present at the National Mental Health Strategy Meeting in Ha Long City. The SFU team was invited to share Canadian perspectives on community-based mental health care, lessons learned, and opportunities for Vietnam and on child and youth mental health services in Canada. This, and other such meetings, also provided the opportunity for the further development of the collaboration between UoM and SFU

These initiatives have all contributed to the ongoing collaboration of MAC-FI investigators with policy makers in MOLISA and $\mathrm{MoH}$.

\section{The MAC-FI Study}

The MAC-FI study is a partnership between researchers at SFU/CARMHA (Canada), PHAD (Vietnam), the University of Melbourne (Australia), MOLISA, MoH, and representatives of NGOs working in mental health in Vietnam. The MAC-FI study is testing the effectiveness of a Supported Self-Management (SSM) intervention for treating mild to moderate depression in 
Vietnam. SSM is a treatment approach for chronic illness management that acknowledges the key role of the patient in recognizing, treating, and managing their own care (Bilsker, Goldner et al. 2012). For depression, SSM is a low-cost and effective intervention that is built on the principles of cognitive behavioural therapy, in which providers support individuals with depression to learn mood management and coping skills through encouragement and coaching support, including goal setting and regular check-ins (Bilsker, Goldner et al. 2012). It is feasible for integration into community-based primary care settings by non-specialist providers, including social workers. SSM treatment is an example of a "frugal innovation" - low-barrier and requiring minimal resources - to address some of the growing global mental health challenges (Howitt, Darzi et al. 2012). SSM and has been recommended for use in both high- and low- income countries (Patel, Simon et al. 2009, National Collaborating Centre for Mental Health 2010). Despite this, evidence is needed about the effectiveness of SSM in low- and middle-income countries.

MAC-FI uses a stepped-wedge, cluster-randomized design, involving patients from eight provinces in Vietnam: Thanh Hoa, Thai Nguyen, and Quang Ninh in Northern region, Da Nang, Quang Nam, and Khanh Hoa in Central region, and Long An and Ben Tre in Southern region. Participants were recruited from two communes (municipal subdivisions) in two districts of each of the eight provinces, for a total of 32 communes. Randomization occurred at the communes level, whereby patients were randomized to receive either the SSM intervention immediately or enhanced treatment as usual, consisting of trained health and social workers monitoring patients and providing them with an educational leaflet that provides information about depression. Patients in the control group were also offered the SSM intervention two months post baseline. This ensured that evidence-based services were not denied to members of a control group. Intervention training, in the form of a course, was delivered to primary health care workers, social workers, and "social collaborators" - volunteer, community-based lay social workers. The SSM intervention uses the Antidepressant Skills Workbook (Bilsker and Paterson 2009) which was developed by mental health specialists at SFU. The Self-reporting Questionnaire-20 (SRQ-20), a 20-item outcome measure with demonstrated validity in the Vietnamese context for measuring depression (Giang, Allebeck et al. 2006, Murphy, Goldner et al. 2015) was the main outcome measure. Additionally, we administered as a secondary measures the World Health Organization's Disability Assessment Scale (WHODAS 2.0) to examine changes in functional ability and the Cut-down, Annoyed, Guilty, Eye-Opener (CAGE) tool to examine the co-occurrence of depression and alcohol misuse. Preliminary results, at the time of writing, are promising and will be submitted for publication in late 2018.

Importantly, the MAC-FI project is built on established partnerships with key partners, including MOLISA and the Ministry of Health. MOLISA is a key partner on the MAC-FI project, and have been involved from the early stages, making this work timely and context-appropriate. They actively engage in program implementation and planning. Training standards for social workers and collaborators are the responsibility of MOLISA, which is considering plans to expand their training to include the SSM intervention.

$\mathrm{MoH}$ is also an important partner in the scale-up of the SSM intervention. The team envisions 
primary care providers ultimately participating in the delivery of the model. Both MOLISA and $\mathrm{MoH}$ have expressed their commitment to improved collaboration to maximize the reach and impact of this intervention to improve community-based mental health services in Vietnam. As described below, we have continually engaged with MOLISA and $\mathrm{MoH}$ stakeholders as key knowledge users to ensure the evidence from the study is relevant and to promote uptake of research findings.

\section{MAC-FI Policy Engagement Processes and Activities}

Since its inception, the MAC-FI study has included integrated knowledge translation, or the active engagement of 'knowledge users' (Goldner, Jenkins et al. 2014, Kothari, McCutcheon et al. 2017), as an fundamental part of the study design, allowing for early and ongoing engagement with policy makers to promote buy-in and a sense of ownership. MAC-FI was preceded by a feasibility study that tested the validity and acceptability of SSM for depression in one rural and one urban commune of Hanoi and assessed the feasibility of conducting the fullscale RCT (Murphy, Oanh et al. 2018). The feasibility study helped to build and strengthen relationships with stakeholders from MOLISA's Department of Social Protection (DSP) and $\mathrm{MoH}$, leading to increasing buy-in and collaboration by policy makers.

The collaboration with MOLISA was strengthened in early 2014, when Atlantic Philanthropies, a private charitable foundation, which at the time was supporting MOLISA to implement the mental health program in Vietnam, contacted PHAD asking them to provide technical support to the mental health program. At this time, MOLISA was struggling to find an appropriate mental health model to implement at the community level with the participation of social workers and collaborators. Because the feasibility study was taking place concurrently with collaboration from MOLISA's DSP, PHAD was able to introduce the SSM model to MOLISA's broader Mental Health Technical Advisory Committee. MOLISA then decided to expand the SSM model to two additional provinces of Vietnam (Thanh Hoa and Ben Tre). The engagement of MOLISA policy makers in the feasibility study and their decision to expand the intervention beyond the initial pilot sites in Hanoi created a window of opportunity for ongoing collaboration to further test and scale-up the SSM intervention.

Following the feasibility study, which yielded promising results (Murphy, Oanh et al. 2018), the study team was invited to submit a 'transition-to-scale' proposal by Grand Challenges Canada. The MAC-FI study proposal process represented a successful collaboration with MOLISA, who committed to invest matched funding in the equivalent of CAD $\$ 549,000$ in the project. This was a considerable commitment, reflecting their policy priority to improve community-based care for depression in Vietnam. We were successful in obtaining funding for the MAC-FI study, which was launched in 2016 with MOLISA as the primary government partner.

In the MAC-FI study, the engagement with policy makers at MOLISA led to the modification of the delivery of the SSM intervention in a way that allowed for enhanced community-based outreach and service delivery. Beginning in 2010, MOLISA designated social work as a profession in Vietnam and allocated USD $\$ 130$ million for social worker training (Durst, Lanh et 
al. 2015). As part of the development of social work in Vietnam, MOLISA envisioned a role for social workers in the delivery of community-based mental health care. This led to an opportunity for the involvement of social workers and social collaborators (volunteer lay social workers) in the delivery of SSM through MAC-FI. In the pilot study the SSM intervention was delivered entirely by primary care providers working at commune health stations under the jurisdiction of $\mathrm{MoH}$. In the MAC-FI study screening for depression continued to take place in primary care settings, with patients subsequently referred to social workers and social collaborators who delivered the coaching component of the intervention. The inclusion of social workers and social collaborators in the MAC-FI study allowed for the delivery of depression care to be shared between the health and social services sector. It also responded to findings of the pilot study that suggested help-seeking for depression in primary care in Vietnam is low and that there is a need for community outreach to ensure that services reach vulnerable people in the community (Murphy, Corbett et al. 2018, Murphy, Goldner et al. 2018, Murphy, Oanh et al. 2018).

Throughout the MAC-FI project investigators from Vietnam, Canada and Australia have continually collaborated with MOLISA representatives on project progress. In May 2016, an official project launch meeting was held at MOLISA's offices in Hanoi, bringing together representatives from SFU, PHAD, MOLISA and the Departments of Health (DoH) in the eight participating provinces. The participation of $\mathrm{DoH}$ representatives was crucial to engaging health sector representatives at the provincial level, who are essential to the implementation of the program. In March 2017, we held an additional planning and update meeting with MOLISA in Hanoi to discuss project progress and implications for scale-up.

The research team hosted a stakeholder engagement workshop in Melbourne, Australia from April 2-6, 2018 to disseminate preliminary findings, to further strengthen the partnerships between SFU, MOLISA, and MoH, and to enhance the engagement of government ministries. A large delegation of individuals from government attended the workshop, led by senior officials from MOLISA, MoH, and the Ministry of Planning and Investment (MPI). MPI is an important new partner in these discussions and will determine any new budget allocations necessary for program scale-up.

The delegation wished to learn more about the Australian mental health care system to help inform the healthcare reform currently taking place in Vietnam. They were particularly interested in learning how to efficiently train a large number of social workers and psychiatrists to meet the mental health needs of the population with mental illness and substance use disorders by providing appropriate services at the community level, in line with their strategy of moving away from institutionalization in large hospitals. Delegates attended site-visits to community organizations (e.g., MIND, one of the largest community mental heath service providers in Australia) and governmental departments (e.g., Department of Health and Human Services), among others. Delegates recognized the importance of focusing on human resource development, research, and intervention to fill the gap in care and indicated they would convey strategies and governance structures they learned during the workshop back to Vietnam to support its healthcare reform, focusing on social and health care workers providing tailored community-based mental health services, including the SSM model. 
This workshop was also a vehicle through which the team discussed logistical and regulatory changes that are necessary to promote the future scale-up of the SSM intervention and to enhance treatment for depression in the social services and primary care sectors. Our partners at MOLISA previously described the need to improve collaboration with $\mathrm{MoH}$ to promote continued scale-up of the SSM model given that the two Ministries work in parallel to provide mental health services to the population in Vietnam. The workshop was successful in strengthening this collaboration, thus helping to facilitate continued conversations on scale-up of the model supporting joint action for mobilizing global mental health policy.

In 2017, our research team, again in partnership with MOLISA, submitted an application to the Canadian Institutes of Health Research Project Grant to conduct a longitudinal qualitative study of implementation factors affecting the scale-up of the SSM model in 'real time'. The team was successful in obtaining funding and the study, "Implementation Research to Improve Scale-up of Depression in Vietnam" (IRIS-DSV)", represents an opportunity for ongoing collaboration and policy engagement with MOLISA and other ministries over the next five years. This new project highlights the growth of our partnerships and the crucial level of commitment that stakeholders have expressed in regards to concrete post-grant scale-up activities. We are confident that this new funding will only continue to strengthen the relationships we have developed between SFU, MOLISA, MoH, UoM, and PHAD, along with other government and non-governmental stakeholders in Vietnam. Findings from MAC-FI and IRIS-DSV have immense potential to contribute to global mental health intervention research, and provide strategic opportunities for engagement in ongoing planning and policy development for enhanced mental health services in Vietnam.

\section{Facilitators and Challenges for Policy Engagement}

The MAC-FI project is founded on collaboration and policy engagement between study investigators and partners in the Vietnamese government. In particular, the partnership with MOLISA has been fundamental to the success of the project thus far, and to securing funding to continue research and implementation of the SSM intervention.

A number of facilitators have helped to advance the process of policy engagement for community-based depression care in Vietnam. Primarily, as described above, the MAC-FI study builds upon two decades of engagement for mental health policy development by the University of Melbourne. The MAC-FI project and the preceding feasibility study were timely, as the government of Vietnam was developing the National Mental Health Strategy and had committed to enhancing improved community-based mental health services. This policy window was an essential facilitator of engagement with policy makers and to obtaining support and buy-in, including in the form of matched funds, for the program. Policy windows such as emerging mental health policies and legislation have been recognized as essential for stakeholder engagement and facilitating scale-up of mental health interventions in other global mental health contexts (Eaton, McCay et al. 2011, Davies and Lund 2017). In the case of MAC-FI, the 
prioritization of mental health by both MOLISA and MoH was essential for the momentum of the program and the active engagement of policy makers.

Existing relationships that are fostered over time are also an important facilitator of stakeholder engagement (Lavery, Tinadana et al. 2010). The MAC-FI project was also able to mobilize the relationship between the Vietnamese principal investigator and policy makers, a relationship that has been crucial to the policy engagement process. Trained as a physician at the Hanoi Medical School and with extensive experience working in Vietnam, the local Principal Investigator (VCN), has a strong connection with the health care system in Vietnam, particularly with senior managers at $\mathrm{MOH}$ and MOLISA. In Vietnam, having legal status and knowing the people in the system are crucial facilitators of success. With more than 25 years of experience working to implement primary health care programs in Vietnam, VCN has had numerous opportunities to work with, present research evidence and to provide assistance to many professional staff who are now working in senior government positions. This long history of engagement has helped to enable the introduction of new ideas and research findings to policy makers. In addition, understanding the local context and needs of policy makers are essential factors of success. Mental health services have long been a neglected area in Vietnam. The government of Vietnam recognized the importance of mental health care services but struggled to identify an efficient, appropriate and cost effective intervention that could be introduced at the primary care and community level. The existing relationship and trust between VCN and PHAD and government officials created an opportunity for engagement around innovative approaches to community-based depression care.

Another important facilitator of policy engagement in the MAC-FI project has been the existence of committed champions within MOLISA. The Vice-Minister of MOLISA has been supportive of the community-based mental health mandate. The Director General of the Department of Social Protection (NVH) has consistently supported the program since the pilot study phase, and has been instrumental in the ongoing collaboration and commitment by MOLISA to the program. He has also played an essential role in convening stakeholders from other ministries including $\mathrm{MoH}$ and the Ministry of Planning and Investment. He is also committed to promoting mental health as a lasting priority area for the government of Vietnam. DSP staff are supportive of this initiative and have worked hard to support the implementation of the MAC-FI project and the broader community-based mental health policy mandate. Champions within organizations and systems have been recognized as essential for program implementation (Yamey 2011, Murphy, Corbett et al. 2018) and the engagement of champions at a senior level has been fundamental to ongoing engagement and collaboration.

As well as the many facilitators of policy engagement, a number of challenges also exist. As is the case in many contexts, inter-ministerial collaboration has been difficult. Historically, MOLISA and $\mathrm{MoH}$ have struggled to collaborate, in part due to disagreements related to jurisdiction and responsibility for mental health service provision. Different views about the required technical skills required to work in mental health have also posed a barrier to collaboration. Advancing coordinated and efficient mental health and social care systems has been challenging, though this objective is now clearly on the agenda through collaboration in Mental Health Consortium 
Project and the collaborative process of developing the National Mental Health Strategy and other initiatives (Minas, Edington et al. 2017). As the MAC-FI project is scaled-up the participation and collaboration of several ministries, including MOLISA, MoH, and the Ministries of Education and Training, Finance, Planning and Investment, and others will be required. Encouraging and supporting this collaboration will be key to successful scale-up.

Though the existence of champions within MOLISA has certainly been a fundamental facilitator of policy engagement for the scale-up of MAC-FI, the reliance on supportive individuals can also be tenuous. Should those champions retire or move to other positions or departments, program support and policy buy-in may decrease considerably. Government mandates and the interests of individuals may change, leading to a change in the level of support for programmes such as SSM. While our existing collaboration with individuals in MOLISA has been a key driver of success, changes in staff and leadership within ministries such as MOLISA are certain to happen and must be factored into planning for sustainability.

Changes at the national level in fiscal policy may also have significant impact on policy and program innovations. Despite the best evidence, if government decides it must implement fiscal restraint in order to manage national finances and resources for the long term, then funding for community-based mental health services could lose support, regardless of the commitment of policy leaders in government. On the other hand, the evidence generated through the MAC-FI project may also be used to justify continued funding despite a general environment of fiscal constraint. Ongoing support from the project team through knowledge mobilization activities, however, may help to mediate the effects of fiscal constraint. Though sociopolitical and economic change may create a precarious environment for policy development in areas that with tenuous support such as mental health, periods of change also represent opportunities for knowledge translation and policy engagement (Lee, Zappelli et al. 2015). The IRIS-DSV study will support at least five years of ongoing engagement with policy makers in Vietnam, enabling us to engage in ongoing knowledge translation activities and allowing both researchers and policy makers to plan for and adapt to changes in the mental health system and broader environment.

\section{Opportunities for future mental health policy engagement}

The MAC-FI project will end in March 2019, while the current iteration of the National Mental Health Program will end in 2020. This creates a significant need for knowledge translation, through which the results of MAC-FI may inform further policy development for communitybased mental health in Vietnam. The IRIS-DSV study, launched in the fall of 2018, will examine implementation factors related to scale-up of the SSM model, and will track, in 'real time', the sociopolitical factors influencing scale-up of SSM through the country over the course of five years. This demonstrates the importance of both intervention and implementation research for informing evidence-based policy and scale-up of mental health services. Our collaboration with MOLISA will continue and will include providing evidence, capacity development support and assistance with convening multijurisdictional stakeholders to inform the ongoing development of mental health policy and service delivery in Vietnam. 


\section{Conclusion and Lessons Learned}

Though the policy context in which the MAC-FI study has taken place is unique to Vietnam, our experience highlights a number of factors that may be of relevance to others seeking to engage with policy makers to promote the scale-up of global mental health innovations in LMICs. First, the nature and process of policy engagement is key. Building on existing relationships that have been fostered over time has proven essential. These existing relationships led to the identification and active involvement of champions within government ministries who have been critically important in supporting the scale-up of the SSM model, including through the investment of matched funds. Using integrated knowledge translation approaches, including involving policy makers in study design and holding regular meetings to communicate emerging findings and plan for next steps, has also been crucial.

Awareness of the policy context and the needs of policy makers has been also been key to policy engagement. The prioritization of community-based care for depression by the government of Vietnam and the interest in training a cadre of social workers and collaborators to provide community-based mental health care made the introduction of SSM timely and wellreceived. Through ongoing collaboration and communication with government partners we have also been able to be responsive and open to emerging needs and opportunities, as shown in the shift in service delivery model between the feasibility study and MAC-FI RCT.

Our experiences in policy engagement through the MAC-FI study also provide important lessons about the role of researchers in the policy process. As mental health policy and services develop in countries like Vietnam, there is a need for ongoing knowledge translation to support evidence-informed policy and service planning. Beyond the communication of research results, there is also an important role for research organizations to play as facilitators and conveners. By bringing together policy makers across several ministries, project teams can support multi-sectoral communication and collaboration. As evidenced by the meetings held in Melbourne in 2018, there is also a demand for opportunities to learn from other contexts and for capacity development related to mental health services and system strengthening. These roles may not always be obvious to researchers working in $\mathrm{GMH}$, but are vitally important facilitators of the policy process.

We have described a number of lessons learned and factors that have contributed to successful policy engagement through the MAC-FI project in Vietnam. Policy engagement, however, is complex and ever-changing. Global mental health innovation and policy engagement take place in real-world, dynamic settings which face considerable resource constraints, changing sociopolitical and economic landscapes and unanticipated challenges. These realities are difficult to avoid and navigate and each context is unique. Despite these challenges and differences, the facilitators described in this chapter may help to guide the policy engagement process in other contexts, and to support the scale-up process of mental health innovations, improving access and availability of care for people living with mental illness in LMICs. 


\section{References}

Beinecke, R. H., H. Minas, S. Goldsack and J. Peters (2010). "Global mental health leadership training programmes." International Journal of Leadership in Public Services 6: 63-72.

Bilsker, D., E. M. Goldner and E. Anderson (2012). "Supported Self-Management: a simple, effective way to improve depression care." Can J Psychiatr. 57.

Bilsker, D. and R. Paterson (2009). The antidepressant skills workbook. CARMHA, Vancouver.

Caldas de Almeida JM, H. Minas and C. Cayetano (2014). Generating Political Commitment for Mental Health System Development. Global mental health: principles and practice. V. Patel, H. Minas, M. Prince and A. Cohen. New York, Oxford University Press

Collins, P., M. Tomlinson, R. Kakuma, J. Awuba and H. Minas (2014). Research Priorities, Capacity and Networks In Global Mental Health. Global mental health: principles and practice. M. H. Patel V, Cohen A, Prince M. New York, Oxford University Press: 425-449.

Davies, T. and C. Lund (2017). "Integrating mental health care into primary care systems in lowand middle-income countries: lessons from PRIME and AFFIRM." Global Mental Health 4: e7.

Durst, D., T. H. Lanh and M. Pitzel (2015). "A Comparative Analysis of Social Work in Vietnam and Canada: Rebirth and Renewal." Journal of Comparative Social Work 5(2).

Eaton, J., L. McCay, M. Semrau, S. Chatterjee, F. Baingana, R. Araya, C. Ntulo, G. Thornicroft and S. Saxena (2011). "Scale up of services for mental health in low-income and middleincome countries." The Lancet 378(9802): 1592-1603.

Fisher, J., M. C. Mello, V. Patel, A. Rahman, T. Tran, S. Holton and W. Holmes (2012). "Prevalence and determinants of common perinatal mental disorders in women in low- and lower-middle-income countries: a systematic review." Bull World Health Organ 90.

Fisher, J., T. Tran, T. Duc Tran, T. Dwyer, T. Nguyen, G. J. Casey, J. A. Simpson, S. Hanieh and B.-A. Biggs (2013). "Prevalence and risk factors for symptoms of common mental disorders in early and late pregnancy in Vietnamese women: a prospective populationbased study." J Affect Disord. 146.

Giang, K. B., P. Allebeck, G. Kullgren and N. Tuan (2006). "The Vietnamese Version of the Self Reporting Questionnaire 20 (SRQ-20) in detecting mental disorders in rural Vietnam: a validation study." Int J Soc Psychiatry. 52.

Goldner, E. M., E. K. Jenkins and B. Fischer (2014). "A Narrative Review of Recent Developments in Knowledge Translation and Implications for Mental Health Care Providers." Canadian Journal of Psychiatry 59(3): 160-169.

Goldner, E. M., J. Murphy and D. Ho (2015). Assessment of the mental health service system of the Social Welfare and Labour Sector. Hanoi, Vietnam, UNICEF and MOLISA.

Howitt, P., A. Darzi, G.-Z. Yang, H. Ashrafian, R. Atun, J. Barlow, A. Blakemore, A. M. J. Bull, J. Car and L. Conteh (2012). "Technologies for global health." Lancet. 380.

Hung, P. M., H. I. Minas, Y. Liu, G. Dahlgren and W. C. Hsiao, Eds. (2000). Efficient, Equity Oriented Strategies for Health-International Perspectives-Focus on Vietnam. Melbourne, Centre for International Mental Health.

Hung, P. M., I. H. Minas, Y. Liu, G. Dahlgren, W. C. Hsiao, H. Duong, H. Luu and Q. Nguyen, Eds. (2001). Cham Soc Suc Khoe Nhan Dan Theo Dinh Huong Cong Bang Va Hieu Qua (Efficient, equity-oriented strategies for health: International perspectives, focus on Vietnam). Hanoi, Hanoi Medical Publishing Company.

Izutsu, T., A. Tsutsumi, H. Minas, G. Thornicroft, V. Patel and A. Ito "Mental health and wellbeing in the Sustainable Development Goals." The Lancet Psychiatry 2(12): 10521054.

Kakuma, R., H. Minas and M. Dal Poz (2014). Strategies for Strengthening Human Resource for Mental Health. Global mental health: principles and practice. V. Patel, H. Minas, A. Cohen and M. Prince. New York, Oxford University Press.

Kakuma, R., H. Minas, N. Ginneken, M. R. Dal Poz, K. Desiraju, J. E. Morris, S. Saxena and R. M. Scheffler (2011). "Human resources for mental health care: current situation and strategies for action." Lancet. 378.

Kohn, R., S. Saxena, I. Levav and B. Saraceno (2004). "The treatment gap in mental health care." Bull World Health Organ. 82. 
Kothari, A., C. McCutcheon, I. D. Graham and I. K. T. R. N. for the (2017). "Defining Integrated Knowledge Translation and Moving Forward: A Response to Recent Commentaries." International Journal of Health Policy and Management 6(5): 299-300.

Lavery, J. V., P. O. Tinadana, T. W. Scott, L. C. Harrington, J. M. Ramsey, C. Ytuarte-Nuñez and A. A. James (2010). "Towards a framework for community engagement in global health research." Trends in Parasitology 26(6): 279-283.

Lee, K., R. Zappelli, E. M. Goldner, N. C. Vu, K. K. Corbett and J. Murphy (2015). "The political economy of mental health in Vietnam: key lessons for countries in transition." Asia \& the Pacific Policy Studies 2(2): 266-279.

Luong, N. K., D. C. La, L. V. N. Truong, T. T. Ha, N. La and H. Minas (2016). Viet Nam. ASEAN Mental Health Systems. H. Minas. Jakarta, ASEAN Secretariat.

Minas, H. (1994). "Vietnam." Australasian Psychiatry 2(6): 280-284.

Minas, H. (1997). "Psychiatry in Vietnam." Australasian Psychiatry 5(1): 3-10.

Minas, H. (2009). Technical assistance to restructure system of centres for care of mental health patients run by MOLISA: Report to WHO Vietnam on a consultancy: 16pp.

Minas, H. (2012). "The Centre for International Mental Health approach to mental health system development." Harv Rev Psychiatry 20(1): 37-46.

Minas, H. (2014). Human security, complexity and mental health system development. Global mental health: principles and practice. V. Patel, H. Minas, A. Cohen and M. Prince. New York, Oxford University Press.

Minas, H., C. Edington, N. La and R. Kakuma (2017). Mental Health in Vietnam. Mental Health in Asia and the Pacific: Historical and Cultural Perspectives. H. Minas and M. Lewis. Boston, MA, Springer US: 145-161.

Murphy, J., K. K. Corbett, D. T. Linh, P. T. Oanh and V. C. Nguyen (2018). "Barriers and facilitators to the integration of depression services in primary care in Vietnam: a mixed methods study." BMC Health Services Research 18(1): 641.

Murphy, J., E. Goldner, K. K. Corbett, M. Morrow, V. C. Nguyen, D. T. Linh and P. T. Oanh (2018). "Conceptualizing depression in Vietnam: Primary health care providers' explanatory models of depression." Transcult Psychiatry 55(2): 219-241.

Murphy, J., E. M. Goldner, C. H. Goldsmith, P. T. Oanh, W. Zhu, K. K. Corbett and V. C. Nguyen (2015). "Selection of depression measures for use among Vietnamese populations in primary care settings: a scoping review." International Journal of Mental Health Systems 9: 31.

Murphy, J., P. T. Oanh, C. H. Goldsmith, W. Jones and V. C. Nguyen (2018). "Introducing supported self-management for depression to primary care in Vietnam: A feasibility study in preparation for a randomized controlled trial." Fam Syst Health 36(2): 210-215.

National Collaborating Centre for Mental Health (2010). National Institute for Health and Clinical Excellence: Guidance. Depression: The Treatment and Management of Depression in Adults (Updated Edition). Leicester (UK), British Psychological Society

Copyright (c) The British Psychological Society \& The Royal College of Psychiatrists, 2010.

National Psychiatric Hospital No 1. (2002). National epidemiology mental disorder survey. Hanoi, Vietnam. National Psychiatric Hospital No. 1.

Ng, C. H., P. T. Than, C. D. La, Q. Van Than and C. Van Dieu (2011). "The National Community Mental Health Care Project in Vietnam: a review for future guidance." Australasian Psychiatry 19(2): 143-150.

Patel, V., G. Simon, N. Chowdhary, S. Kaaya and R. Araya (2009). "Packages of care for depression in low- and middle-income countries." PLoS Medicine 6(10): e1000159.

Vuong, D. A., E. Ginneken, J. Morris, S. T. Ha and R. Busse (2011). "Mental health in Vietnam: burden of disease and availability of services." Asian J Psychiatr. 4.

World Health Organization (2013). Mental Health Action Plan 2013-2020. Geneva, Switzerland.

Yamey, G. (2011). "Scaling up global health interventions: a proposed framework for success." PLoS Med 8. 